\title{
La vulnerabilidad e invisibilidad de las mujeres ante el VIH/SIDA: constantes y cambios en el tema
}

\author{
Cristina Herrera, Soc, $M$ en $C S_{1}^{(1)}$ Lourdes $C$ ampero, $M$ en $E .^{(2)}$
}

\section{Herrera C, Campero L. \\ La vulnerabilidad e invisibilidad de las mujeres ante el VIH/ SIDA: constantes y cambios en el tema. Salud Publica Mex 2002:44:554-564. El texto completo en inglés de este artículo está disponible en: http://www.insp.mx/salud/index.html}

\section{Resumen}

Este artículo es una reflexión sobre la problemática que viven las mujeres ante el VIH/SIDA. A través de estadísticas mundiales y nacionales que dan cuenta del incremento de la epidemia en las mujeres, se hace evidente la necesidad de atender el problema. Se argumenta cómo la estructura y relaciones de género favo recen la vulnerabilidad de las mujeres, y cómo la vulnerabilidad y el riesgo de infección se incrementan para muchas mujeres al transitar por diversas situaciones específicas, como la migración, la precariedad de empleo y la violencia doméstica, entre otras. Se enuncian los principales obstáculos que enfrentan las mujeres para hacer socialmente visible su situación y necesidades, así como la falta de poder para encarar de manera más eficaz su problemática. Se habla de las iniciativas de la sociedad civil organizada y de las estrategias gubernamentales que se han implantado, así como de sus principales logros, car encias, necesidades y retos. Finalmente, a manera de conclusión y recomendación, se destaca la necesidad de establecer y evaluar programas y políticas de prevención y atención bajo una perspectiva de género y de derechos humanos, que permita una mayor conciencia y mejores respuestas al problema de las mujeres frente al VIH/SIDA. El texto completo en inglés de este artículo está disponible en: http://www.insp.mx/salud/index.html

Palabras clave:VIH/SIDA; género; vulnerabilidad; políticas; México

\author{
Herrera C, Campero L. \\ The vulnerability and invisibility of women facing \\ HIV/AIDS: constant and changing issues \\ Salud Publica Mex 2002;44:554-564. \\ The English version of this paper \\ is available at: http://www.insp.mx/salud/index.html
}

\begin{abstract}
A bstract
This paper presents some thoughts on the problems endured by wo men facing HIV/AID S.W orld and nationwide statistics show an upward trend of the epidemic among wo men, calling for the need to address this problem.A case is made for the way in which gender structure and relations facilitate the vulnerability of women to this disease, increasing their risk of infection related with specific factors like migration, employment unsafe conditions, and domestic violence, among others. Emphasis is made on the main obstacles faced by women to flag their concerns and needs in society, as well as on their lack of empowerment to cope effectively with their problems. Some initiatives advanced by the organized civil society and governmental strategies are presented, including accomplishments, deficiencies, needs, and challenges. Finally, conclusions and recommendations are given, highlighting the need to establish and evaluate preventative programs and policies from a gender and human rights perspective, to promote a greater awareness and improved responses to the problems imposed on women by the HIV/AIDS epidemic.The English version of this paper is available at: http://www.insp.mx/salud/index.html
\end{abstract}

Key words: HIV/AIDS; gender; vulnerability; policies; Mexico

(1) Coordinación del Grupo Latinoamericano de Trabajo en Mujer y SIDA (Glams). Centro de Investigación en Sistemas de Salud. Instituto N acional de Salud Pública. Cuernavaca, Morelos, México.

(2) Centro de Investigaciones en Salud Poblacional. Instituto N acional de Salud Pública. Cuernavaca, Morelos, México.

Fecha de recibido: 13 de mayo de 2002 - Fecha de aprobado: 5 de septiembre de 2002

Solicitud de sobretiros: C ristina Herrera. Centro de Investigación en Sistemas de Salud. Instituto $\mathrm{N}$ acional de Salud Pública. A venida Universidad N 0.655, 1er piso. Colonia Santa María A huacatitlán. Cuernavaca, Morelos, México.

Correo electrónico: cherrera@correo.insp.mx 
E 1 VIH/SIDA afecta cada vez a más mujeres. Este artículo busca evidenciar los aspectos sociales y culturales que las hacen vulnerables en esta epidemia, así como hacer visible el problema, los obstáculos y retos a los que se enfrentan cuando buscan dar respuestas y soluciones a los mismos. El trabajo presenta, en primer lugar, algunas estadísticas actuales de la distribución del VIH/SIDA en el mundo, en particular en México, destacando la situación de las mujeres; en segundo lugar, una revisión sintética de la evolución conceptual seguida durante el transcurso de la epidemia; en tercer lugar, se describe la vulnerabilidad propia de las mujeres y se la analiza desde una perspectiva de género, haciendo especial referencia a la sexualidad como espacio donde se construyen tanto el riesgo como las estrategias de prevención; se incluye, asimismo, una breve discusión sobre las categorías de género, poder, empoderamiento y visibilidad social para luego mencionar los principales obstáculos políticos y culturales que impiden que el problema del VIH/SIDA en las mujeres sea adecuadamente visible; finalmente, se pasa revista a las principales acciones y respuestas intentadas frente a este problema, tanto las generadas por los gobiernos como las que proceden de la sociedad civil organizada y los movimientos sociales, señalando los principales logros, carencias, necesidades y retos. Cierra el trabajo una sección de conclusiones y recomendaciones, con las que esperamos contribuir a una mayor conciencia y mejores respuestas al problema de las mujeres frente al VIH/SIDA.

\section{Situación actual}

\section{El VIH/SIDA en las mujeres, en el mundo y en México}

Como es de amplio conocimiento, el SIDA es una enfermedad infecciosa producida por el virus de la inmunodeficiencia humana $(\mathrm{VIH})$, que se puede transmitir por vía sexual, por transfusión sanguínea y de la madre al hijo, ya sea durante el embarazo, el parto o la lactancia materna. A partir del momento en que el virus entra al cuerpo de la persona infectada pueden pasar de dos semanas a tres meses antes de que aparezcan anticuerpos en su sangre. En promedio, la en-

\footnotetext{
* Algunos grupos defensores de los derechos de las mujeres han propuesto sustituir la noción de "transmisión de la madre al hijo" por la de "transmisión de los padres al hijo", para evitar que se culpabilice a la mujer por la transmisión, y hacer visible el hecho de que en la gran mayoría de los casos es la pareja estable de la mujer quien ya la ha infectado.
}

fermedad tiene un periodo de incubación de 10 años, lo que implica que una persona puede transmitir el virus sin saber que está infectada.

Hasta la fecha se registran más de 24 millones de muertos por SIDA en el mundo. Según datos de diciembre de 2001, a escala global existen 40 millones de personas viviendo con el VIH, de los cuales 37.1 millones son adultos, y de éstos, 18.5, es decir, cerca de la mitad, son mujeres. Durante el año 2001 se infectaron 4.2 millones de adultos, de los cuales casi la mitad fueron mujeres. Estos datos demuestran que, en el ámbito mundial, la brecha inicial que existía entre hombres y mujeres infectados se está reduciendo de manera acelerada y en algunas partes del mundo, incluso, las mujeres infectadas han superado a los hombres. ${ }^{1}$ Las distintas regiones del mundo contribuyen en diferente proporción a estos totales. En Africa sub-sahariana, por ejemplo, $55 \%$ de las personas que viven con el VIH son mujeres, comparadas con $25 \%$ en América Latina, $35 \%$ en El Caribe y 20\% en Europa y Estados Unidos de América (EUA). Las estadísticas comienzan a registrar un nuevo dato preocupante: los niños huérfanos por el SIDA, a la fecha ascienden a 14 millones en todo el mundo.

De todas las personas que viven con el VIH/SIDA en el mundo, 95\% están en países en desarrollo, lo que permitió clasificar al VIH/SIDA como una "enfermedad de la pobreza". Actualmente la epidemia se concentra en las áreas marginales de las grandes ciudades de los países en desarrollo y, de manera creciente, en zonas rurales.

Se ha dicho que el SIDA no es una epidemia sino varias, y muestra diferentes patrones según el contexto geográfico y social en donde aparece. Actualmente, se habla de tres patrones básicos de transmisión. El patrón 1, que predomina en Europa y EUA, se caracteriza por tener como primera vía de transmisión las relaciones homo y bisexuales, y en segundo lugar al uso intravenoso de drogas; el patrón 2, característico de Africa, tiene como primera vía las relaciones heterosexuales, y como segunda, las transfusiones sanguíneas en condiciones inadecuadas; el patrón 3, patrón intermedio, tiene como primera vía las relaciones homo y bisexuales, y como segunda las transfusiones sanguíneas. ${ }^{2,3}$ Este último es el que predomina en México, si bien gracias a las políticas de control de la sangre implantadas tempranamente, la vía por transfusión sanguínea casi ha desaparecido.

Aun cuando en México la epidemia se concentra en hombres que tienen sexo con hombres (HSH), existen algunas diferencias regionales: mientras que en los estados del norte del país crece la transmisión vinculada al uso de drogas, en especial en las zonas de fron- 
tera, en los estados del sur, y en particular en las zonas rurales, se incrementa la transmisión heterosexual/bisexual del VIH y aumenta la infección en mujeres y la transmisión perinatal. Las estadísticas actuales muestran que en México alrededor de 15\% de las personas infectadas son mujeres y, si bien existe polémica al respecto, se sospecha que este número se incrementa, tal como reportan las personas que trabajan con la comunidad en muchos estados del país, particularmente en las zonas de frontera y rurales. En la frontera sur y en estados pobres (Chiapas, Tlaxcala, Hidalgo y Puebla), hay tres hombres por cada mujer infectada, lo que se aleja de la proporción nacional: seis hombres por una mujer. ${ }^{4}$

\section{Evolución conceptual sobre la epidemia}

Desde que apareció el VIH/SIDA hubo una evolución conceptual en la forma de caracterizar a la epidemia: de la idea de "grupos de riesgo" se pasó a la de "prácticas de riesgo", luego a la de "situaciones y contextos de riesgo", y finalmente a la de "condiciones sociales del riesgo", lo que dio lugar al concepto de vulnerabilidad.

Aparecida la epidemia se hicieron intervenciones ineficaces y excluyentes con los llamados "grupos de riesgo", recomendando la abstinencia y el aislamiento como formas de prevención. Sin embargo, cuando se conoció más acerca del virus, la idea de "grupos de riesgo" dio paso a la de "comportamiento de riesgo". Esta idea, si bien trató de quitar el estigma a esos grupos, promoviendo la participación de todos, tendió a culpabilizar a los individuos por los fracasos en la prevención. El modelo de cambio de comportamientos basado sólo en ofrecer información, fue criticado al señalar que dichos comportamientos están fuertemente determinados por desigualdades sociales como las de género, etnia, edad, preferencia sexual o clase social.

La noción de vulnerabilidad, que proviene del área de los derechos humanos, ${ }^{5}$ originalmente designaba a grupos o individuos fragilizados jurídica o políticamente en la promoción, protección o garantía de sus derechos de ciudadanía. Ahora bien, aplicada al campo del SIDA, amplía el horizonte de los estudios, acciones y políticas dirigidos a controlar la epidemia, ya que supera la noción de riesgo individual (traducido en acciones dirigidas a "grupos de riesgo" y "comportamientos de riesgo") para acceder a una nueva comprensión de la vulnerabilidad social.

La distinción es importante, ya que "mientras el riesgo apunta hacia una probabilidad y evoca una conducta individual, la vulnerabilidad es un indicador de inequidad y desigualdad social y exige respuestas en el ámbito de la estructura social y política". ${ }^{6}$ De esta manera, la noción de vulnerabilidad, con sus distintas facetas, permite comprender por qué es más adecuado hablar de "vidas que transcurren en el riesgo, que de prácticas de riesgo". ${ }^{7} \mathrm{Al}$ entender las diferencias entre riesgo y vulnerabilidad, podemos ver que esta última determina los riesgos diferenciales y sobre ella debe actuarse. ${ }^{6}$ Las condiciones estructurales de desigualdad social en las que viven las mujeres son el principal factor de su vulnerabilidad.

\section{La vulnerabilidad de las mujeres ante el VIH}

Existen vulnerabilidades diferenciadas para hombres y mujeres, muchas de las cuales son consecuencia del proceso por el cual la sociedad dicta diferentes pautas de comportamiento a cada uno de los géneros, como se verá más adelante. Aquí, sin embargo, hablaremos específicamente de aquellas vulnerabilidades que afectan a las mujeres, ya que consideramos importante, además de hacer visible su especificidad, poder identificar algunas de las determinantes de estas vulnerabilidades, asociadas al hecho de pertenecer al sexo y al género femeninos. La vulnerabilidad de las mujeres tiene múltiples rostros: biológico, epidemiológico, social y cultural.

Para el caso de la vulnerabilidad biológica se ha comprobado que en las relaciones heterosexuales la mujer es de 2 a 4 veces más vulnerable a la infección por el VIH que el hombre, porque la zona de exposición al virus durante la relación sexual es de mayor superficie en la mujer, porque la carga viral es mayor en el semen que en los fluidos vaginales, y porque las infecciones de transmisión sexual (ITS) (co-factores de infección por el VIH) son más frecuentemente asintomáticas y no tratadas en la mujer que en el hombre, ${ }^{8}$ lo que debilita la mucosa vaginal permitiendo la entrada del virus, más aún en las adolescentes, cuyo aparato genital todavía está inmaduro.

Epidemiológicamente los patrones de formación de pareja vigentes en la gran mayoría de las sociedades llevan a que mujeres más jóvenes mantengan relaciones sexuales y establezcan pareja con hombres de mayor edad, lo que hace que dichas mujeres estén en un riesgo mayor de infectarse por el VIH y demás ITS, debido a que practican sexo desprotegido con hombres de una franja de edad en la que son más elevados los niveles de prevalencia del VIH e ITS. Por otro lado, las mujeres suelen necesitar más transfusiones sanguíneas que los hombres. ${ }^{9}$

En cuanto a la vulnerabilidad social, las mujeres del tercer mundo siguen teniendo menor acceso a la educación y al trabajo asalariado, lo que las vuelve más 
dependientes de los hombres y con escasas posibilidades de acceder a información y a servicios adecuados de salud. Es importante notar que la cuestión central aquí es que "los dos géneros son tratados desigualmente en términos políticos, culturales y socioeconómicos, lo que puede observarse tanto en el ámbito de las parejas y familias, como de la sociedad o de las culturas nacionales o supranacionales". ${ }^{10}$

Se ha definido al género como la construcción social de la diferencia entre los sexos, ${ }_{1}^{11}$ es decir, las expectativas compartidas acerca del comportamiento adecuado de hombres y mujeres en una determinada sociedad, como se ejemplificará más adelante.

La vulnerabilidad de las mujeres por cuestiones de género se refuerza cuando, además, se suman otras desigualdades como la pobreza o la discriminación por razones étnicas o de preferencias sexuales, es decir, el VIH/SIDA afecta a las mujeres en tanto mujeres, pero no las afecta a todas por igual. Si bien existe una vulnerabilidad específica para las mujeres, aquellas que están particularmente en riesgo son las trabajadoras de la salud, las compañeras sexuales de personas que tienen prácticas de riesgo, las parejas sexuales de personas que viven con el VIH, las mujeres expuestas a situaciones especiales de riesgo como abuso sexual, violencia, transfusiones sanguíneas sin precaución, y las mujeres indígenas/rurales, migrantes o parejas de migrantes, las mujeres privadas de la libertad o parejas de personas privadas de la libertad, entre otras. Una gran proporción de mujeres pertenece a uno o más de estos "grupos", y tiene así "vulnerabilidades acumuladas". Un ejemplo de esta situación es el de las mujeres migrantes, que además de la vulnerabilidad específica de género -que las convierte constantemente en víctimas de violencia y abuso y a veces de infección por el VIH-, pierden al migrar sus derechos de ciudadanía, sus redes sociales y sus recursos, lo que muchas veces las obliga a practicar sexo de supervivencia o a tolerar maltratos que, en una situación de menor vulnerabilidad, no tolerarían. ${ }^{12}$ Género, origen étnico, situación socioeconómica, status de ciudadanía, entre otras formas de discriminación, se combinan así para formar situaciones de vulnerabilidad acumulada y, por lo tanto, extrema.

\section{Género y sexualidad, dimensiones de riesgo}

En nuestras sociedades, el género y la sexualidad están culturalmente determinados, vale decir, son modos de distinguir y jerarquizar a las personas que no vienen dictados por la anatomía y fisiología de sus cuerpos sino por representaciones, valores y discursos socialmente construidos. Aunque analíticamente distinguibles, el género y la sexualidad están estrechamente vinculados entre sí, y no sólo representan formas de clasificación, socialización diferenciada o división sexual del trabajo, sino que son fundamentalmente relaciones de poder.

El término poder, de manera general, alude a una "fuerza ejercida por individuos o grupos"13 pero tiene dos acepciones: poder como facultad o capacidad y poder como dominio. En nuestra sociedad, tanto en la concepción sociológica clásica como en el sentido común, el poder es visto como lo segundo, es decir la capacidad de ejercer dominio o control sobre personas y cosas en el marco de una relación jerárquica de autoridad/subordinación. Para Max Weber, la autoridad es la "posibilidad de encontrar obediencia a un mandato determinado contenido entre personas dadas". ${ }^{14}$ En esta acepción, el poder sería "toda dominación duradera del hombre sobre el hombre que se apoya sea en la fuerza, sea en la legitimidad, lo que le permite hacerse obedecer sin reparos" ${ }^{15}$ Estas definiciones permiten ver que el poder como fenómeno social duradero, nunca se apoya exclusivamente en la fuerza sino que en general incluye un elemento de legitimidad o consentimiento por parte de los subordinados. En El Contrato Social, Rousseau establece que "El más fuerte no es nunca bastante fuerte para ser siempre el amo, si no transforma su fuerza en derecho y la obediencia en deber". ${ }^{16}$ Las fuentes de la legitimidad pueden ser diversas, una de las más importantes, como sugiere Rousseau, es el carácter legal del orden establecido. No obstante, la desigualdad de poder también se apoya en mitos, en una visión del mundo armónica y legítima, y se expresa en normativas que se viven cotidianamente en instituciones sociales como la familia y el parentesco, la escuela, las instituciones religiosas, la legislación, etcétera, produciendo y reproduciendo identidades y subjetividades individuales y colectivas. Fue el filósofo francés Michel Foucault quien amplió la comprensión sobre el fenómeno del poder, al establecer una distinción entre el poder encarnado en estructuras (el Estado, la Iglesia, etcétera) y el poder como normas disciplinarias que operan a través de representaciones, actitudes y discursos institucionales. Estos discursos a su vez construyen sujetos, pero el poder no se localiza en un lugar específico. El resultado es "un cuadro donde el poder está disperso de forma desigual a lo largo de la red social y cultural, configurando campos de fuerza inestables" ${ }^{17}$ El poder está siempre presente, en todas partes y en estado fluido, lo que permite observar que los subordinados siempre ejercen algún tipo de poder, muchas veces en for- 
ma de resistencia. Siguiendo los planteamientos de Foucault, los "micromecanismos" del poder producen críticas que -en caso de contar con organización política- podrían convertirse en estrategias para resistir a los propios mecanismos del poder. De esta manera el poder es inherente a la sociedad y a las relaciones humanas. Tal vez podamos decir que lo que es ética y moralmente inaceptable es el abuso del poder. Los abusos de poder no son unilaterales: todo individuo puede encontrarse en posiciones de opresión y subordinación en determinados momentos, pero algunas de las estructuras de poder son más trascendentes y más consistentes que otras. ${ }^{13}$ La de sexo-género es una de ellas, y como todo sistema de clasificación y jerarquización social, supone un conjunto de procesos a partir de los cuales ciertas condiciones sociales (en este caso basadas en una diferencia biológica) adquieren un carácter opresivo, convirtiendo al orden simbólico en subordinación. No obstante, en virtud del consentimiento y la legitimidad que el poder suele implicar, la mayor parte del tiempo la subordinación no es vivida como tal por los sujetos dominados. Se trataría de un poder múltiple, localizado en muy diferentes espacios sociales, que puede revestirse de "los más nobles sentimientos de afecto, ternura y amor", ${ }^{18}$ o como señala Bourdieu, las formas de dominación pueden ser sutiles e incluso consentidas y aceptadas por los sujetos dominados como algo que está en la naturaleza de las cosas, constituyendo "una 'violencia simbólica' invisible para sus propias víctimas, que se ejerce, en último término, a través de las vías del sentimiento". ${ }^{19}$

Los ideales sexuales establecidos para hombres y mujeres forman parte del sistema simbólico que algunos autores han llamado sistema de sexo-género. ${ }^{20,21}$ Estos sistemas consisten en "conjuntos de prácticas, símbolos, normas, representaciones sociales y valores que dan sentido a la satisfacción de los impulsos sexuales, a la reproducción y al relacionamiento entre las personas como seres sexuados ${ }^{\prime \prime}{ }^{18}$ constituyendo así el objeto de estudio clave para comprender la subordinación femenina -dominación masculina en una determinada sociedad. En este sistema, como en muchos otros de clasificación social, se establecen desigualdades que colocan a unos en situación de dominar y a otros de ser dominados. Tal es, por ejemplo, la asignación de roles de género: las mujeres en la esfera de lo doméstico y de la reproducción, los hombres en la de la producción y de lo público. Pero la sexualidad no es ajena a estos esquemas. Históricamente y por diversos motivos, la dominación masculina implicó la necesidad de controlar las capacidades reproductivas, productivas y sexuales de las mujeres, siendo proba- blemente las formas discursivas de control de estas últimas las más resistentes a los cambios sociales y culturales.

Así, el ideal sexual femenino tradicional, en la mayor parte de las sociedades, espera ciertos comportamientos y actitudes en las mujeres que a su vez garanticen el control de la reproducción: virginidad antes del matrimonio -muchas veces confundida con la idea de inocencia y ésta con ignorancia de las cuestiones sexuales-, pasividad, no reconocimiento o expresión del deseo sexual, obligación de complacer a la pareja más allá de su propio deseo o voluntad, fidelidad sexual a la pareja y orientación a la procreación como principal motivo para ejercer la sexualidad. En contrapunto, el ideal de la masculinidad implica que el hombre ante todo debe ser heterosexual, activo, tener múltiples conquistas sexuales, no necesita saber sobre sexo porque lo sabe todo, tiene un impulso incontrolable que debe satisfacer de inmediato, debe ser fuerte y arriesgado, e invulnerable.

Las características mencionadas como ideales, tanto femenino como masculino, obstaculizan de manera preocupante las posibilidades de una prevención eficaz del VIH, ya que si bien estas normas no son obedecidas al pie de la letra por todos los individuos, sí determinan muchas de las prácticas sexuales de riesgo en hombres y mujeres de amplios sectores, en la medida en que dificultan un disfrute consciente y responsable de la sexualidad, como ejemplificaremos más adelante.

Los factores de la cultura de sexo-género que incrementan la vulnerabilidad de las mujeres, pero también la de los hombres, lo hacen a través de su influencia directa o indirecta en las prácticas sexuales. Por una parte las mujeres tienden a ignorar o bien aceptar pasivamente las múltiples parejas del compañero, que en más casos de los que se acepta son también otros hombres. La llamada bisexualidad masculina, que como se ha documentado es una práctica bastante común en nuestra Región, ${ }^{22}$ algunas veces tiene como contracara y causa indirecta a la homofobia, es decir, el rechazo social a la homosexualidad, que puede llegar a adquirir rasgos de violencia extrema. Este rechazo obliga a algunos hombres -que de lo contrario asumirían con mayor libertad sus preferencias sexuales- a llevar una doble vida, teniendo en algunas ocasiones prácticas homosexuales, al mismo tiempo que mantienen una imagen social de heterosexuales y "padres de familia", incluso ante sí mismos. Más aún, en ciertos contextos culturales, muchas veces se cree que el tomar la parte "activa" en una relación entre hombres no solamente deja intacta la identificación con la hete- 
rosexualidad, sino que antes bien, refuerza la hipermasculinidad (machismo). En determinados grupos de la sociedad esta compleja configuración de la sexualidad masculina constituida por prácticas bisexuales no reconocidas, implica aún más riesgo: el no asumir abiertamente esta preferencia sexual, hace que muchos hombres asistan a lugares semiclandestinos donde mantienen relaciones sexuales sin protección, comúnmente precedidas por un fuerte consumo de alcohol o drogas, como sustancias que liberan pero a la vez relajan los cuidados. El reprimir este deseo hace que no se vaya "preparado" a tener una relación sexual ocasional, por ejemplo, llevando y usando condones, lo que incrementa el riesgo de infectarse o de infectar a otros(as). ${ }^{22}$ Una situación similar sucede con la valoración social de la virginidad en la vida de las mujeres solteras. Este requisito social hace que muchas jóvenes no "anticipen" sus encuentros sexuales premaritales y los tengan sin haber tomado medidas de protección. Otro gran "malentendido compartido", producto también de la construcción social de la sexualidad, es la idea de que sólo los jóvenes tienen relaciones sexuales, lo que impide que muchas mujeres y hombres mayores sexualmente activos, consideren la conveniencia de hacerse la prueba del VIH o de usar condones en sus encuentros sexuales.

Finalmente, la sexualidad femenina está muy fuertemente marcada por las nociones del amor romántico, no sólo en la juventud sino también en la madurez. Con la idealización del enamoramiento muchas mujeres legitiman sus deseos sexuales, y dan a la sexualidad un significado afectivo y a veces "irracional", que en muchas ocasiones impide un ejercicio más libre y responsable de la sexualidad. Al hablar de negociación del uso del condón muchas veces se asume que las mujeres, a diferencia de los hombres, siempre quieren usarlo. Sin embargo, el ejercicio de la sexualidad basado en la noción de amor romántico implica, para muchas, un ideal de amor sin condiciones ni infidelidades por lo que el condón es visto como señal de pérdida de confianza en la pareja, haya o no fundamentos para tenerla. Para otros la sexualidad implica renuncia, sufrimiento y desigualdad como constitutivos del lugar de lo femenino. ${ }^{23}$ Estos factores agravan el problema de la falta de conciencia de riesgo en las mujeres, en especial las monógamas que basan su ideal de vida en el ideal de la pareja estable, la confianza y la supuestamente mutua fidelidad. El resultado es la imposibilidad de pensar en la necesidad de sexo más seguro y menos aún de practicarlo. Apropiarse del propio cuerpo y de sus deseos es fundamental para establecer relaciones de mayor reciprocidad entre hombres y mujeres, y para adoptar conductas preventivas.

\section{Empoderamiento social vs. invisibilidad de las mujeres}

Como señalan algunas autoras feministas, el mito del "poder femenino" en el sistema de dominación masculina puede producir hostilidad, temor e inquietud en quienes ejercen la dominación, en la medida en que "se teme a quien se domina porque no se lo conoce, ya que es privilegio del poderoso no tomarse la molestia de conocer a quien está bajo su yugo, y la conducta del dominado, en la medida en que pone en evidencia que las razones por las que legitimó su poder son falsas, despierta la hostilidad del dominador". ${ }^{24}$ Este desconocimiento por parte del poderoso se relaciona directamente con el concepto de invisibilidad social. Metafóricamente se dice que ciertos grupos subordinados o excluidos "no son visibles" o "no tienen voz", para evocar la incapacidad de quien ejerce el poder de "verlos y oírlos", es decir, reconocer su existencia social, condiciones de vida, necesidades, derechos o aportes a la sociedad y a la cultura. La invisibilidad de ciertos grupos suele ser producto de la "negación" de la existencia de algo incómodo, amenazante o indeseado para el orden social. Supone la exclusión o negación de existencia social o ciudadanía a determinados grupos, que quedan así convertidos en una "alteridad silenciosa" -o en todo caso hablada por el discurso dominante-. El lenguaje dominante sirve para invisibilizar. La definición de poder citada más arriba (donde el poder se define como el "dominio del hombre sobre el hombre"...), por ejemplo, impide diferenciar el dominio del hombre sobre el hombre del dominio del hombre sobre la mujer, invisibilizando a esta última y a la misma relación de poder entre los géneros.

Debido a su estrecha relación con el poder, un proceso de visibilización supone adquirir la capacidad de hablar en nombre propio, de hacerse notar y de salir de lo privado para reclamar acceso a o representación en el espacio público, la investigación, los sistemas médicos y la toma de decisiones políticas. La visibilidad de los grupos dominados por el sistema de sexo género, en general ha sido posible en diferentes momentos históricos gracias al análisis crítico del discurso hegemónico (por ejemplo feministas, gays y lesbianas) y a la acción política. ${ }^{17}$

Existen diferentes obstáculos para la visibilidad de las mujeres ante el VIH/SIDA, tanto en México como en la mayor parte de los países. A pesar de que un número importante de los nuevos casos de VIH/ SIDA se ha presentado entre mujeres monógamas, sigue existiendo el estereotipo de que el SIDA es una enfermedad de hombres gays y de que, si acaso existe 
algún riesgo para las mujeres, éste es tan sólo para las trabajadoras sexuales y usuarias de drogas intravenosas. Como ha sido ya muy discutido, al aparecer la epidemia de SIDA, grupos estigmatizados de antemano por tener una sexualidad considerada "anormal" -homosexuales-, por no sujetarse a las normas tradicionales del género femenino -trabajadoras sexuales-, o bien por tener prácticas consideradas delictivas -usuarios de drogas-, sirvieron de chivo expiatorio y fueron rápidamente asociados con el riesgo, dejando fuera de él, entre otros grupos, a la gran mayoría de las mujeres. En consecuencia, muchas mujeres que están en riesgo por su pareja, ignoran esta vulnerabilidad, más aún cuando a través de la educación se les ha enseñado que la familia es un espacio seguro y el riesgo aparece solo al salir de ella. ${ }^{25,26}$ Esto se agrava con una cultura sexual caracterizada por la doble moral -que establece diferentes derechos y libertades para hombres y mujeres- y la homofobia, que llevan a muchos hombres, como ya se mencionó, a mantener una doble vida sexual.

Otro gran obstáculo para la visibilidad de las mujeres es la ausencia de voces que reivindiquen sus necesidades, frente a una epidemia que cada vez las afecta más: muchos grupos de activistas por los derechos y la salud de las mujeres no han dado al tema del SIDA un lugar prioritario en sus agendas políticas, ${ }^{27,28} \mathrm{y}$ en las organizaciones de lucha contra el SIDA en general ha prevalecido la preocupación por otros grupos. Además, nuestros sistemas políticos y un contexto de escasos recursos obligan a que grupos que de otro modo no tendrían motivos de enfrentamiento, disputen entre sí por su visibilidad ante el sector público y por el reconocimiento de que sus necesidades son más genuinas y su vulnerabilidad mayor, lo que los haría merecedores de la atención y los recursos. Un problema adicional es que el VIH afectó más a aquellas mujeres de grupos minoritarios o segmentos de clase con menor acceso a la educación formal, en una época en la que, para entrar a la consideración de la política, las necesidades deben estar formuladas en el código de la política -ser parte de la opinión pública, ser capaces de transformarse en derechos o de trascender a las personas biográficas para convertirse en "temas políticos"-. ${ }^{29}$ Sin este código, las demandas no tienen oportunidad de entrar al circuito político y volverse visibles para el público y las políticas; y para que los grupos "invisibles" ganen una audiencia -en particular ante una crisis médico-política como el SIDA-, deben tener un conocimiento especializado que no se adquiere fácilmente de manera informal o sin la ayuda de gente con cierto nivel de capacitación formal. ${ }^{30}$

La capacidad de hacerse "visibles" en el espacio público, tal como la hemos esbozado, supone un proce- so de empoderamiento para las mujeres más vulnerables. La noción de empoderamiento ha sido muy utilizada por la psicología comunitaria norteamericana ${ }^{31,32}$ pero viene del campo del feminismo. Mientras que la primera vertiente enfatiza el control y dominio personal sobre la vida y el entorno, y hace hincapié en las nociones de control e influencia, algunas autoras feministas ${ }^{33-35}$ se refieren más bien a la transformación del individuo y de la sociedad. A diferencia del anterior (que sería un empoderamiento psicológico), esta versión incluye las relaciones cercanas de las mujeres, una dimensión colectiva, y enfatiza las nociones de autoestima y conciencia -de las estructuras sociales que están fuera de su control inmediato y de las opciones que se les presentan. ${ }^{13}$ Como es fácil de imaginar, el proceso de empoderamiento femenino es largo y complejo, y atañe sólo a las propias afectadas (nadie puede "empoderar" a las mujeres desde fuera, sino apoyarlas en este proceso) y hace referencia a un proceso de restitución de poder que les permita adueñarse de su propia vida y tomar decisiones al respecto. ${ }^{7}$

En relación con el VIH/SIDA, Geeta Gupta* ha identificado seis fuentes distintas de poder (en su acepción de poder como capacidad, más que como dominio): 1. Información y educación, 2. Habilidades, 3. Acceso a servicios y tecnologías de prevención, 4. Acceso a recursos económicos, 5. Capital social y 6. Oportunidad de tener voz en la toma de decisiones en todos los niveles. El empoderamiento abarcaría entonces a todas estas áreas al mismo tiempo. En última instancia, señala esta autora, para revertir el desbalance de poder entre hombres y mujeres se requiere de políticas que se orienten a reducir la brecha de género en educación, acceso a recursos económicos, participación política y protección contra la violencia. Frente a los modelos preventivos del VIH/SIDA que insisten en promover cambios individuales de comportamiento en las mujeres, el enfoque de género llama la atención sobre la dificultad para lograr estos cambios sin el necesario poder para hacerlo, como un recurso básico para la acción. Si la noción de vulnerabilidad es de carácter social, también el empoderamiento, como su opuesto, debe concebirse desde un punto de vista social. En otras palabras, debe significar un cambio en las relaciones desiguales entre los géneros a escala social y no reducirse al objetivo, por ejemplo, de que cada mujer individualmente desarrolle la habilidad de exigir el condón a su pareja.

* Gupta G. Approaches for enpowering women in the HIV/AIDS Pandemic: A gender perspective. Paper preparado para Expert Groups Meeting on "The HIV/AIDS Pandemic and its Gender Implications EGM/HIV-AIDS/2000/EP 4, 1, NOVEMBER, 2000. 
Empoderamiento implica, entonces, trabajar para cambiar las condiciones de vida que colocan a las mujeres en riesgo de infección por el VIH. Esto requiere de una estrategia de fortalecimiento de grupos, conformación de redes y promoción y defensa pública, donde el tema del VIH se incorpore a la agenda del derecho a la salud sexual y reproductiva. Promover el cambio social y trascender así la noción estrecha de empoderamiento femenino, sin embargo, es difícil de lograr en el corto plazo, y mientras ello no ocurra, más mujeres se seguirán infectando. Urge entonces desarrollar métodos de prevención controlados por las mujeres o que no dependan totalmente de la buena voluntad de sus parejas. Al mismo tiempo se debe sensibilizar a los hombres, en especial los jóvenes, en una nueva cultura de género, para desarrollar estrategias eficaces de prevención. Algunas, como el uso del condón con la pareja estable mediante mensajes no rechazantes, o el acuerdo en la pareja para usar condón en todas las relaciones sexuales extramaritales, son alternativas que se han intentado en algunas poblaciones. Sin embargo, los resultados son aun incipientes y de acuerdo con ciertas posturas están lejos del ideal de empoderamiento feminista, en la medida en que son estrategias para que las mujeres se protejan cuando tienen una pareja infiel o incluso violenta, en lugar de alentarlas a salir de esas relaciones. A pesar de esto, pueden ser estrategias de supervivencia útiles para muchas mujeres que están en uniones estables valoradas por ellas, pero en riesgo por la conducta de su pareja. ${ }^{36}$

El ideal sigue siendo, como expresó Geeta Gupta en la XIII Conferencia Mundial de SIDA realizada en julio de 2000 en Sudáfrica, "liberar a hombres y mujeres de normas de género destructivas y de dar poder a las mujeres para cuidarse y participar en la toma de decisiones, lo que no significa quitar el poder a los hombres sino quitarles una falsa idea de poder que incrementa la vulnerabilidad de ambos".

\section{La respuesta social}

\section{La sociedad civil organizada: logros, insuficiencias y necesidades}

Es cada vez más evidente que las respuestas al VIH/ SIDA deben tener un alcance y un enfoque macrosocial. La acción comunitaria y los movimientos sociales organizados adquieren aquí un papel clave. ${ }^{37}$

Con esta preocupación el proyecto Grupo Latinoamericano de Trabajo en Mujer y SIDA (Glams), comenzó a trabajar en 1994 con el apoyo de la Fundación McArthur en el Instituto Nacional de Salud Pública de México, y cuyo objetivo ha sido el de favorecer la visi- bilidad de la situación de las mujeres y de sus necesidades desatendidas, ante sí mismas, la sociedad y el espacio de las decisiones públicas, trabajando en contacto y colaboración con redes y organizaciones (ONG) de la Región latinoamericana y de México. ${ }^{38}$

Este contacto y el conocimiento de muchas experiencias en la Región, nos permite constatar que el papel que la organización civil ha jugado en la epidemia del SIDA ha sido clave. En muchos casos, ha ofrecido una respuesta solidaria, oportuna y apropiada a la creciente demanda por parte de la sociedad ante la carencia o insuficiencia de políticas al respecto. Particularmente en el caso del VIH/SIDA, su trabajo de información y capacitación a la población ha sido de vital importancia.

Sin embargo, el fenómeno de la organización de las propias mujeres alrededor del problema es relativamente incipiente e insuficiente. La demanda creciente de atención por parte de las mujeres ha obligado a algunas organizaciones a asumir una serie de actividades e iniciativas que muchas veces diferían de sus objetivos centrales. Es frecuente, por tanto, que no siempre cuenten con recursos y personal profesional para dar una respuesta idónea al problema. De las iniciativas que conocemos sobre el tema son relativamente pocas las que están dedicadas específicamente a las mujeres y, de éstas, son aún menos las dedicadas exclusivamente a atender su problemática ante el VIH/ SIDA. Algunas lo han hecho como complemento de otras actividades, que van desde la promoción del "desarrollo comunitario" en general, hasta la atención a grupos de personas que viven con el $\mathrm{VIH}$, entre los que comienzan a aparecer las mujeres con problemáticas muy diferentes de las de los hombres afectados. En muchos casos, por tanto, se carece de una perspectiva de género que favorezca un mejor entendimiento de la realidad de las mujeres. Por otro lado, llama la atención el hecho de que muchas iniciativas continúen entendiendo el problema desde el enfoque de los "grupos de riesgo" y, por lo tanto, centren sus estrategias esencialmente en conocer y controlar las prácticas de grupos, como las trabajadoras sexuales. Muchos también, mantienen una idea de empoderamiento sustentada en el desarrollo de habilidades para la negociación del uso del condón, donde el concepto de negociación tiene supuestos cuestionables, como la idea de que se regatea algo valioso en igualdad de condiciones, o que existe comunicación verbal con la pareja. El hecho de que sea el varón quien por lo general tiene múltiples parejas y controla al mismo tiempo el uso del condón, pone en duda esta idea de igualdad en la negociación, ${ }^{26}$ y hace poco confiable esta estrategia. Además, es necesario tener presente que en muchos contextos latinoamericanos, especialmente en 
zonas rurales, la valoración social de la maternidad temprana y de la unión marital hace que muchas jóvenes no deseen "negociar" ningún método anticonceptivo y menos de prevención de ITS/VIH/SIDA, y que en las relaciones sexuales -por lo general muy tempranas-no intercambien valores equivalentes sino, por ejemplo, su virginidad y dar placer sexual al compañero a cambio de una promesa de unión, embarazo mediante.* Otro supuesto que subyace en el enfoque de la "negociación sexual" es que existe conciencia de riesgo en las mujeres, lo cual, como hemos visto, en nuestra Región no siempre existe. Debe mencionarse que muy pocas iniciativas se ocupan de las "amas de casa" -que a falta de una mejor designación, hace referencia a mujeres en uniones monógamas y básicamente dedicadas al hogar- o iniciativas que trabajen con la pareja como tal.

Finalmente, a muchas de las organizaciones de mujeres les falta información actualizada sobre la realidad, carecen del tiempo y los recursos necesarios para hacer evaluaciones de sus acciones $y$, por ambos motivos, insisten en enfoques y estrategias que las desgastan y no arrojan resultados más positivos.

La mayoría de las organizaciones representan esfuerzos importantes, pero muchas veces locales y solitarios; buena parte no están vinculadas y no involucran en su trabajo cotidiano a tomadores de decisiones ni a formuladores de políticas públicas.

\section{La respuesta gubernamental: carencias y retos}

La especificidad del VIH/SIDA en las mujeres está lejos de ser un problema unánimemente reconocido, y más aún de ser considerado una prioridad dentro de las políticas de salud dirigidas a la atención y prevención de la epidemia. Los gobiernos de la Región han incorporado el tema de mujer y SIDA en su retórica, pero en general no lo han traducido en programas concretos dirigidos a las mujeres en tanto tales. A menudo los programas de detección y atención temprana del VIH en mujeres se dan a través de los servicios de atención prenatal y obstétrica. Esto implica que la mayoría de las mujeres infectadas no conocen su seroestatus sino hasta cuando solicitan estos servicios o al ya ser sus hijos positivos al VIH. Inclusive, sólo comienzan a sospechar que están infectadas, cuando su pareja enferma y muere de SIDA.

\footnotetext{
* Szasz I. El estudio de la sexualidad en México, una búsqueda necesaria para abordar problemas de salud reproductiva. México, D.F.: El Colegio de México.
}

En la actualidad, apenas se ha tomado alguna iniciativa enfocada a la transmisión perinatal o al trabajo sexual, reforzando la idea de que la mujer es "transmisora" del virus -ya sea a sus hijos o a sus clientes-, e ignorando su vulnerabilidad y sus derechos. Esto es, muchos de los programas que los gobiernos e instituciones han desarrollado no están específicamente dirigidos a las mujeres.

De acuerdo con ONUSIDA, las estrategias para mejorar las condiciones de la mujer pasan por combatir la falta de información, contar con servicios de salud adecuados, métodos de prevención que dependan de las mujeres, fortalecer programas de desarrollo económico en las mujeres y de equidad de género, y diseñar políticas que tiendan a disminuir la vulnerabilidad.

\section{Conclusiones}

La sexualidad y el SIDA requieren de una reflexión desde la perspectiva de los derechos sexuales y reproductivos, en el contexto de las relaciones de género como relaciones de poder. Los modelos de prevención que exhortan a las mujeres a practicar la monogamia o a insistir en el uso del condón, colocan en ellas la responsabilidad por prácticas y métodos que no controlan, olvidando, al mismo tiempo, la situación real de la mayoría de las mujeres que están en uniones estables.

El cómo abordar esta gran población de mujeres que, en su mayoría, no están en riesgo por sus propios comportamientos sino por prácticas riesgosas de sus parejas, sin siquiera sospecharlo, sigue siendo un problema no resuelto. Un estudio reciente en México* es revelador al respecto, al constatar que la gran mayoría de las mujeres que viven con el VIH en el país contrajeron el virus a través de su único compañero estable. El sexo protegido es visto como algo innecesario por las mujeres que están en uniones monógamas, reforzando las condiciones de vulnerabilidad que venimos exponiendo.

El problema de las mujeres y el VIH/SIDA ha sido percibido cada vez por más grupos y organizaciones, sin embargo, como se ha ido mostrando a lo largo de este trabajo, quedan todavía muchos vacíos, obstáculos y retos por enfrentar, principalmente si se busca dar soluciones desde una perspectiva de género y de derechos humanos.

\footnotetext{
* United Nations Development Fund for Women (UNIFEM). Oficina Regional de México, Centroamérica, Cuba y República Dominicana, Mujeres y VIH/SIDA en México: los escenarios de una relación oculta, México, 2000.
} 
Entre las necesidades más importantes de las organizaciones de la sociedad civil están la profesionalización, la capacitación o actualización de sus miembros, la coordinación de esfuerzos con instituciones de salud y educación; el intercambio de experiencias, trabajo y recursos materiales a escala interinstitucional; y, particularmente, la formación de redes entre las organizaciones que están trabajando con mujeres. ${ }^{39,40}$

En el caso de algunas organizaciones, que están trabajando con la problemática de las mujeres y que han incorporado el concepto de empoderamiento, es necesario que logren trascender la noción de "autoestima" con la que muchas veces se confunde el concepto (reduciéndolo así a un asunto individual y privado) y darle una dimensión social.

En cuanto a las políticas, un mayor compromiso hacia el tema debería traducirse en la visibilidad de las mujeres, en la promoción del enfoque de género en programas y políticas de prevención y atención, la evaluación de las que existen, la difusión e intercambio de las estrategias que funcionan y las que no, y el fortalecimiento de la capacidad de la sociedad civil y en particular de las mujeres líderes.

\section{Referencias}

1.Programa Conjunto de las $\mathrm{N}$ aciones U nidas so bre elVIH/SIDA (O N USIDA). Informe sobre la epidemia mundial de VIH/SIDA. Ginebra: O NUSIDA, 2002.

2. Joint United N ations Programme on HIV/AIDS (UNAIDS). Report on the Global HIV/AIDS Epidemic. Ginebra: UN AIDS, 2000.

3. Grmek M. Historia del SIDA. México, D.F.: XXI Siglo Veintiuno Editores, 1992.

4. Magis C, Bravo E, Rivera P. El Sida en México en el año 2000. En:U ribe $P$, Magis $C$, ed. La respuesta mexicana al SIDA: mejores prácticas. México, D.F.: CON ASIDA, 2000.

5.Ayres JR, França I, C alazans G, Soletti H.Vulnerabilidade e prevenção em tempos de AIDS. En: Barbosa R, Parker R, ed. Sexualidades pelo avesso. Direitos, identidades e poder. Río de Janeiro: IMS/UERJ 1999: 49-72.

6. Izazola JA,A strola L, Beloqui J, Bronfman M, C hequer P, Zacarías F.Avances en la comprensión del VIH/SIDA: una visión multidisciplinaria. En: Izazola JA, ed. EI SIDA en América Latina y EI Caribe: una visión multidisciplinaria. México, D.F.: Fundación Mexicana para la Salud, 1999: 21-44

7. Giffin K. Beyond empowerment: Heterosexualities and prevention of AIDS. Soc Sci Med 1998; 46(2):151-156.

8. Eng TR, Butler W T. The hidden epidemic. W ashington, D.C.: N ational A cademy Press, 1997.

9. Consejo N acional para la Prevención y Control del VIH/SIDA (CO NASIDA). Situación del VIH/SIDA en mujeres y niños. Disponible en: http:// www.ssa.gob.mx/conasida. México, D.F.: consultado en marzo de 2002. 10. Bastos F, Landman C. AID S e pauperização: Principais conceitos e evidencias empiricas. Presentación al Seminario:Violencia Estructural, Desigualdade Social e Vulnerabilidade Frente ao HIV/AIDS, Rio de Janeiro: ABIA, A bril 2000.
11. Lamas M. La antropología feminista y la categoría de género. En: Lamas M, ed. El género: la construcción cultural de la diferencia sexual. México, D.F: Porrúa, 1996: 97-125.

12. Bronfman M, Uribe P, Halperin D, Herrera C. Mujeres al borde... Vulnerabilidad a la infección por VIH en la frontera sur de México. En:Tuñón E, ed. Mujeres en las fronteras: trabajo, salud y migración (Belice, Guatemala, Estados Unidos y México). México, D.F.: El Colegio de la Frontera Norte/El Colegio de la Frontera Sur/El Colegio de Sonora/Plaza y Valdés Editores, 2001: 15-31.

13.Townsend J,Zapata E. Introducción. En:Zapata E,Townsend J, Rowlands J,Alberti P, Mercado M, ed. Las mujeres y el poder. México, D.F.: Plaza y Valdés, 2002:225-228.

14.W eber M. Economía y sociedad. México, D.F.: Fondo de Cultura Económica, 1964:21

15. Sau V. Diccionario ideológico feminista. Voz poder. Barcelona: Icaria La mirada esférica, 2000;vol. 1:240-247.

16. Rousseau J. El Contrato Social o Principios de derecho político; D iscurso sobre las ciencias y las artes; Discurso sobre el origen de la desigualdad. México, D.F.: Porrúa, 2000.

17. Correa S. Commentary. En: Culture, Health \& Sexuality. vol. 3, N 0.1, 2000:339-349.

18. De Barbieri T. Sobre la categoría género: una introducción teóricometodológica. En: Isis Internacional, 1992; Ediciones de las Mujeres núm. 17:111-128.

19. Bourdieu P. La dominación masculina. Barcelona:A nagrama, 2000.

20. 0 akley A. Sex, gender and society. Londres:Temple Smith, 1972.

21. Rubin G. El tráfico de mujeres: notas sobre la "economía política" del sexo. En: Lamas M. El género: la construcción cultural de la diferencia sexual. México, D.F: Porrúa, 1996: 35-96.

22. Liguori AL, Aggleton P.Aspectos del comercio sexual masculino en la Ciudad de México. En: Debate feminista, 1998; 18(9): 152-185.

23.Avila MB. Direitos reproductivos, exclusao social eAids. En: Barbosa R, Parker $\mathrm{R}$, ed. Sexualidades pelo avesso. Direitos, identidades e poder. Rio de Janeiro: IMS/UERJ, 1999: 39-48.

24. Hierro G. Etica y feminismo. Citado en: Sau V. Diccionario ideológico feminista. Barcelona: Icaria-La mirada esférica, 2000:240-247 Vol.1.

25. Barbosa R,VilellaW .A Trajetoria feminina daA IDS. En:Parker R, G alvao J, ed. Q uebrando o silencio. Mulheres e AIDS no Brasil. Rio de Janeiro: ABIA y IMS/UERJ, 1996: 17-32.

26. Barbosa R. N egociacao sexual ou sexo negociado? Poder, genero e sexualidade emTempos de AIDS. En: Barbosa R, Parker R, ed. Sexualidades pelo avesso. Direitos, identidades e poder. Rio de Janeiro:IMS/UERJ, 1999: 73-88.

27.Vandale $S$, Liguori AL, Rico B. Una agenda latinoamericana de investigación-acción sobre mujeres y SIDA. En: Rico B,Vandale S,Allen B, Liguori $A L$, ed. Situación de las mujeres y elVIH/SIDA en A mérica Latina. México, D.F.: Instituto N acional de Salud Pública, 1997: 29-36.

28. Herrera C , C ampero L. N eeds of Latin A merican W omen in the face of AIDS and the N GO response. En: XII International AIDS Conference. Social Science. Rights, Politics, Commitment and Action. Bologna, Italia. Monduzzi Editore, 2000: 427-431.

29. Bronfman M, Herrera C. Descentralización y participación en salud: nuevos aportes para la discusión. En: Briceño R, De Souza C, Coimbra C, coord. Salud y equidad: una mirada desde las ciencias sociales. Rio de Janeiro: Ed. Fiocruz, 2000:243-262.

30. Patton C.W omen, W rite,AID S. Preface. En: Roth N , Hogan K, ed. Gendered epidemic. Representations of women in the age of AIDS. Nueva York (NY): Routledge, 1998:9-13.

31. Rappaport J. Empowerment meets narrative: Listening to stories and creating settings. Am J Community Psychol 1995;23(5):795-808 (citado por Townsend J, 2002, op.cit.).

32. Zimmerman MA. Psychological empowerment: Issues and Illustrations.Am J C ommunity Psychol, 1995;23(5):581-599 (citado por Townsend J, 2002, op.cit.). 
33. Batliwala S. The meaning of women's empowerment: $\mathrm{N}$ ew concepts from action. En: Sen G, Germain A, Chen L, ed. Population policies reconsidered: $H$ ealth, empowerment and rights. Boston (MD): Harvard University Press, 1994:127-38, (citado por Townsend ).A péndice. En:Zapata E, Townsend J, Rowlands J, Alberti P, Mercado M. Las mujeres y el poder. México, D.F.: Plaza y Valdés, 2002:225-228).

34. Kabeer N . Reversed realities: Gender hierarchies in development thought. Londres:Verso, 1994 (citado por Townsend J, 2002, op. cit.).

35. Rowlands J.A word of the times, but what does it mean? Empowerment in the discourse and practice of development. En:Afshar $\mathrm{H}$, ed.W $\mathrm{O}$ men and empowerment: Illustrations from the Third World. Londres: McMillan, 1998 (citado por Townsend J, 2002, op.cit.).

36. 0 'Leary. Preventing HIV infection in heterosexual women; what do we know? W hat must we learn? Appl Preventive Psychol 1999; (8): 257263.
37. Mann J,Tarantola JMD, N etter TW, ed. AIDS in the W orld. N ueva York (N Y): 0 xford University Press, 1996.

38. Campero L, Herrera C. Improving comunication based on the needs of Latin A merican women in the face of AIDS, En: X II International AIDS Conference. Social Science. Rights, Politics, Commitment and Action. Bologna, Italia. Monduzzi Editore, 2000: 523-527.

39. Hernández AM, C asanova E. Las O N G que trabajan sobre el SIDA y las mujeres. En: González S, ed. Las organizaciones no gubernamentales mexicanas y la salud reproductiva. México, D.F.: El Colegio de México, 1999: 97-123.

40. Pérez H, LunaA, Hernández JJ. Fortaleciendo nuevos liderazgos y acrecentando las capacidades entre las organizaciones no gubernamentales con trabajo en VIH/SIDA menos favorecidas en los estados en México. México, D.F.: Colectivo Sol A.C./The MacArthur Foundation and the U.S. Embassy, 2000. 